\title{
Clinical or Surgical Study of Warm-e-Mararah (Cholecystitis)
}

Md. Reyazuddin ${ }^{1}$, Mohammad Ali, ${ }^{1}$ Md Tanwir Alam ${ }^{2 *}$

1. Dept. of Ilmul Jarahat, DUMC Hospital \& Research Centre, Deoband(UP), 2. Dept. of Preventive \& Community Medicine, Govt. Tibbi College \& Hospital, Patna, Bihar

\begin{abstract}
Cholecystitis is a medical condition where inflammation occurs in gallbladder. This condition can be associated with or without the presence of gallstones. Bacterial infection accounts for $50 \%$ to $85 \%$ of the disease's onset. Since there is a close relationship between the biliary system and the gut. In Unani system of medicine SBM and MDW, are compound formulation is effective in the treatment of Amraz-e-Jigar and may be useful in the treatment of Warm-eMarara also. So the aim of this study is to evaluate the efficacy of Unani Formulation on scientific parameters. This study was an open observational study, carried out on 40 patients. The test drug was given in the form of decoction with $7 \mathrm{gm}$ Majoon Dabeedulward with $50 \mathrm{ml}$ Sharbat Bazoori Motadil twice a day after meal for the period of 2 months. All the patients of were assessed fortnightly on subjective parameters $\left(0^{\text {th }}, 15^{\text {th }}, 30^{\text {th }} 45^{\text {th }}\right.$ and $60^{\text {th }}$ day $)$ whereas objective parameters were assessed before and after the treatment. The outcome of intervention was analyzed using appropriate statistical methods. The subjective parameters of pain in abdomen, nausea \& vomiting, dyspepsia and loss of appetite were satisfactorily alleviated by the test drugs and all the findings found in USG and CT scan were also seen to subside within the protocol duration. The findings about the parameters suggest that the test drug was effective in Warm-e-Marara and the cure was substantial. It reduced the subjective parameters as well as the findings in USG and CT scan of the Warm-e-Marara patients.
\end{abstract}

Keywords: Acute Cholecystitis; Warm-e-Marara; Majoon Dabeedulward; Sharbat Bazoori Motadil. 


\section{INTRODUCTION}

Cholecystitis is a medical condition where inflammation occurs in gallbladder. ${ }^{1}$ This condition can be associated with or without the presence of gallstones. ${ }^{2}$ It is classified in to two types i.e., acute cholecystitis and chronic cholecystitis. ${ }^{3}$ It is found both in men and women but may have a propensity for certain populations. ${ }^{2}$

Acute cholecystitis is defined as inflammation of the gallbladder and is usually caused by obstruction of the cystic duct, ${ }^{4}$ whereas Chronic cholecystitis is a prolonged, sub-acute condition caused by the mechanical or functional dysfunction of the emptying of the gallbladder. ${ }^{3}$

Acute cholecystitis (AC) is one of the most common surgical diseases. Bacterial infection accounts for $50 \%$ to $85 \%$ of the disease's onset. Since there is a close relationship between the biliary system and the gut..$^{5}$

Acute cholecystitis is most often caused by gall stones. Gall stones are one of the most common disorders of the gastrointestinal tract, affecting about $10 \%$ of people in Western society and more than $80 \%$ of people with gall stones are asymptomatic whereas acute cholecystitis develops in 1$3 \%$ of patients with symptomatic gall stones. ${ }^{6}$

Acute calculous cholecystitis (ACC) is the most frequent complication of cholelithiasis and represents one-third of all surgical emergency hospital admissions. ${ }^{7}$ According to WHO, Gallstone disease is a major health problem in particularly, in developed world. It is also one of the leading causes of digestion-related hospital admissions with high healthcare costs in these countries. $^{8}$

Helminthic infection (ascariasis) is a major cause of biliary disease in developing countries in Asia, southern Africa, and Latin America. Obstruction of the cystic duct causes an inflammatory process to start. This results in acute cholecystitis. If the inflammation persists it may cause perforation or gangrene of the gall bladder. ${ }^{9}$ Over $90 \%$ of cases of acute cholecystitis result from obstruction of the cystic duct by gall stones or by biliary sludge that has become impacted at the neck of the gall bladder. ${ }^{10}$ Obstruction of the cystic duct causes the intraluminal pressure within the gall bladder to increase and, together with cholesterol supersaturated bile, triggers an acute inflammatory response. The trauma caused by the gall stones stimulates the synthesis of prostaglandins $\mathrm{I}_{2}$ and $\mathrm{E}_{2}$, which mediate the inflammatory response. ${ }^{11}$

Secondary bacterial infection with enteric organisms (most commonly Escherichia coli, Klebsiella, and Streptococcus faecalis) occurs in about $20 \%$ of cases. ${ }^{12}$ biliary sludge is a mixture of particulate matter and bile, and it may stimulate microlithiasis. If the sludge persists- 
for example, because the patient has already had several pregnancies or is receiving total parenteral nutrition-gall stones can form. ${ }^{13}$ Acute cholecystitis (AC) is a life-threatening emergency that commonly occurs as a complication of gallstones. ${ }^{14}$ Severe right upper quadrant pain, abdominal guarding, fever, and a positive Murphy's sign with an elevated white blood cell count are the classical clinical manifestations of AC. ${ }^{15}$

Although ultrasonography is typically the initial diagnostic examination in patients with suspected AC, computed tomography and magnetic resonance imaging are commonly performed to identify complications; cholecystography is recommended in patients with equivocal findings on the other imaging modalities, as this technique has the highest diagnostic accuracy in the diagnosis of AC. ${ }^{16}$

Imaging studies are also helpful in the timely detection of complications associated with AC. Although laparoscopic cholecystectomy is considered the gold-standard treatment for $\mathrm{AC},{ }^{17}$ percutaneous gallbladder drainage with or without cholecystectomy tube placement is a safe, effective management technique for surgically high-risk patients with multiple medical conditions. ${ }^{18}$

This treatment can be used as either a bridging therapy, with elective cholecystectomy performed at a later time after improvement of the patient's condition, or as definitive treatment in surgically unfit patients. ${ }^{19}$ Radiologists play a pivotal role in the initial diagnosis and management of patients with AC. ${ }^{20}$ Cholescintigraphy is the most sensitive imaging modality for cholecystitis. ${ }^{21}$ Complications of acute cholecystitis have a characteristic CT appearance and include necrosis, perforation, abscess formation, intraluminal hemorrhage, and wall emphysema. ${ }^{22}$ There is various allopathic medicines available for the management of cholecystitis like ursodeoxycholic acids, NSAID, Opium derivatives etc., have various side effects. $^{23}$

Unani Scholars also described about Amraze Mararah, under the caption of Amraze Jigar, they also mentioned that inflammation occurs in the Mararah is due to Ghaleez wa fasid ghiza, ehtebas ghair tabayi. ${ }^{24}$

Most of the Great Unani scholars like Hippocras, Galen, Zakaria Razi, Ali Ibn Abbas Majusi, Ibn-e-Sina, Ismail Jurjani, Ibn-e-Hubal Baghdadi etc., are described about the pathophysiology of this disease and also their treatment method by Mufarrad wa Murakkab Drugs like; Kasni, Mako, Karafs, Tukhm Soya, Khare Khasak, Hajrul Yahud, Afsanteen, Duqu, Habbul Qilt, Sirka, Arque Kasni, Arque Mako, Arque Ajwain, Majun Hajrul Yahood etc. ${ }^{25}$ Currently most of them are scientifically proved for their lithotripsy, analgesic, hypolipidemic activities. ${ }^{26}$ 
So this study was conduct as a clinical trial using Unani formulation title as "Clinical or Surgical Study of Warm-e-Marara (Cholecystitis)" on scientific parameters.

After obtaining ethical clearance from Institutional Ethical Committee, Deoband Unani Medical College, Hospital \& Research Centre, Deoband, as an open labeled interventional without control pre and post analysis study, Sample size was 40 (both male \& female) only interventional group, Diagnosed case Warm-e-Marara and Patients who have agreed to sign the informed consent form and follow up the protocol, Patients were kept under strict observation and advised to come fortnightly in OPD for the assessment of study till the completion of study. Sixty days study was divided into four visits of follow up, which were made at an interval of 15 days. At every visit, patients were asked about the progression or regression in their symptoms and subjected to assess the clinical findings.

The study outcome measures of baseline are compared with each follow ups in terms of subjective and objective parameters as per protocol. A total of 80 patients were screened, out of which 40 cases fulfilling the inclusion criterion based on thorough history, clinical examinations. Certain investigations were carried out with the aim to exclude the patients with pathological conditions mentioned under exclusion criteria and to assess the efficacy of treatment group and to establish the safety of the test drug.

\section{Objective of The Study}

To evaluate the efficacy of Unani formulation in Warm-e-Mararah (Cholecystitis) as conservative treatment.

\section{MATERIALS AND METHOD}

The present clinical study entitled "Clinical or Surgical Study of Warm-e- Mararah (Cholecystitis)" was conducted at OPDs of DUMC Hospital \& Research Centre, Deoband (UP) from June 2017 to September 2018. The study was executed after obtaining approval of the study protocol from the Institutional Ethical Committee, Deoband Unani Medical College, Hospital \& Research Centre, Deoband. The study protocol comprises of following subheadings.

\section{Criteria for selection of cases}

\section{Inclusion criteria:}

- Patients of age group between 30-55 years.

- Patients of either sex.

- Diagnosed case of cholecystitis

- Radiological Evidence of Cholecystitis 
- Patients who have agreed to sign the informed consent form and follow up the protocol.

\section{Exclusion criteria:}

- Patients of age group between 30-55 years.

- Patients below 30 years and above 55 years.

- Uncontrolled Diabetes \& Hypertension

- Pregnant and lactating women.

- Patient undergoing treatment for other serious illness.

\section{Selection of subjects}

After the screening, during the selection of the patients, complete history including general physical and systemic examination was carried out and recorded on a prescribed case report form which was designed according to the objectives of the study. A detailed history was recorded regarding their chief complaints with duration, age, sex, religion, marital status, occupation, address, socioeconomic status on the basis Kuppaswamy's socioeconomic scale. Personal history, treatment history, past history of any disease and family history were also recorded in a predesigned proforma. After history taking, general physical examination was done with special emphasis on height (in $\mathrm{cm}$ ), weight (in $\mathrm{kg}$ ), pulse rate/minute; blood pressure in $\mathrm{mm}$ of $\mathrm{Hg}$, any other positive finding during general physical examination was recorded in CRF. Likewise, a careful systemic examination of cardiovascular system, respiratory system, renal system, gastrointestinal system was also done to look for any findings of other serious illness. After that detailed examination specific to the diabetes mellitus was carried out in all the patients.

\section{Assessment of Temperament}

Determination of temperament (Mizaj) was done on the based on Ajnas-e-Ashra (10 different parameters) mentioned in Unani literature. These parameters have been shown in the table attached with the case report form in annexure.

\section{Informed consent}

Patients coming under the inclusion criteria mentioned above were given the information sheet having details regarding the nature of the study, the drug to be used, method of treatment etc and explained verbally also about study. Patients were given enough time to go through the contents of informed consent sheet. They were given the opportunity to ask any question and if they agreed to participate in the study, they were asked to sign the informed consent form.

\section{Investigations}


Certain investigations were carried out with the aim to exclude the patients with pathological conditions mentioned under exclusion criteria and to assess the efficacy of treatment group and to establish the safety of the test drug.

Following investigations were done in each and every case before and after the treatment to evaluate the efficacy of Unani formulation in warm-e-meda.

- Total Bilirubin

- SGOT

- $\quad$ SGPT

- Alkaline Phosphate

- Blood Urea

- Serum Creatinine

- Endoscopy

\section{Method of Collection of Data:}

- Clinical interview

- Laboratory investigations.

\section{Subjective parameters:}

- Pain in abdomen

- Nausea \& Vomiting

- Dyspepsia

- Loss of appetite

\section{Objective parameters:}

- USG whole abdomen

- CT whole abdomen

\section{Study design:}

The study was designed an open observational study.

\section{Sample size:}

The sample size was 40 diagnosed patients.

\section{Allocation of subjects:}

Forty research subjects were single arm as test group with sample size of 40 .

\section{Duration of protocol:}

The treatment period was determined as 60 days. 


\section{Follow up during treatment:}

Patients were kept under strict observation and advised to come fortnightly in OPD for the assessment of disease till the completion of study. Sixty days study was divided into four visits of follow up, which were made at an interval of 15 days. At every visit, patients were asked about the progression or regression in their symptoms and subjected to assess the clinical findings.

\section{Test drug: Composition of Research Drug - As Decoction}

\begin{tabular}{llll}
\hline S. No & Common Name & Scientific Name & Weight \\
\hline 1 & Tukhm Kasni & Chicorium intybus & $25.0 \mathrm{gm}$ \\
2 & Tukhm Kheera & Cucumis sativus & $25.0 \mathrm{gm}$ \\
3 & Tukhm Kakri & Cucumis melo & $25.0 \mathrm{gm}$ \\
4 & Tukhm Kharbuzah & Cucumis melo & $25.0 \mathrm{gm}$ \\
5 & Beekh Kasni & Chicorium intybus & $50.0 \mathrm{gm}$ \\
6 & Shakkar & Saccharum officinarum & $1.0 \mathrm{Kg}$ \\
\hline
\end{tabular}

Method of preparation, dosage and mode of administration of test drug:

Above test formulation ingredients is procured from market in the form of raw materials and makes Sharbat in pharmacy of DUMC Hospital and Research Centre, as per National Formulary of Unani Medicine (NFU) medicine with GMP.

\section{Dose of Research Drug:}

The decoction given with $7 \mathrm{gm}$ Majoon Dabeedulward with $50 \mathrm{ml}$ Sharbat Bazoori Motadil twice a day after meal for the period of 2 months.

\section{Withdrawal criteria:}

- Failure to follow the protocol therapy.

- The cases in which adverse drug reaction is noticed

\section{Adverse drug documentation:}

No adverse event or reaction was noted during the test or control drug administration.

\section{Methods:}

The GCP (Good Clinical Practice) was adopted and regular monitoring was done as per prescribed Case Record Form (CRF).

\section{Documentation:}

The CRF and informed consent forms were submitted to the Dept. of Ilmul Jarahat after completion of the trial.

\section{Statistical analysis:}


Descriptive and inferential statistical analysis has been carried out in the present study. Results on continuous measurements are presented on Mean \pm SD (Min-Max) and results on categorical measurements are presented in Number (\%). Significance is assessed at $5 \%$ level of significance. The following assumptions on data is made, Assumptions: 1. Dependent variables should be normally distributed, 2. Samples drawn from the population should be random, Cases of the samples should be independent

Student $\mathrm{t}$ test (two tailed, dependent) has been used to find the significance of study parameters on continuous scale within each group. Chi-square/ Fisher Exact test has been used to find the significance of study parameters on categorical scale between two or more groups, Nonparametric setting for Qualitative data analysis. Fisher exact test used when cell samples are very small.

Paired Proportion test has been used to find the significance of proportion in paired data. Smaller percentage of Improvement becomes significant at lower tail compared to higher tail. Eg. Improvement from $10 \%$ to $20 \%$ is difficult than the Improvement from $80 \%$ to $90 \%$.

\section{Significant figures}

+ Suggestive significance $(\mathrm{P}$ value: $0.05<\mathrm{P}<0.10)$

* Moderately significant ( $\mathrm{P}$ value: $0.01<\mathrm{P} \leq 0.05$ )

** Strongly significant ( $\mathrm{P}$ value: $\mathrm{P} \leq 0.01$ )

Statistical software: The Statistical software namely SPSS 18.0, and R environment ver.3.2.2 were used for the analysis of the data and Microsoft word and Excel have been used to generate graphs, tables etc.

\section{RESULTS AND OBSERVATION}

Study design: An observational clinical study

Table 1: Mizaj distribution of patients studied

\begin{tabular}{lll}
\hline Mizaj & No. of patients & $\%$ \\
\hline Damvi & 4 & 10.0 \\
Safravi & 28 & 70.0 \\
Saudavi & 8 & 20.0 \\
Total & 40 & 100.0 \\
\hline
\end{tabular}

Table 2: Pain in Abdomen- An assessment at different time intervals of patients studied

\begin{tabular}{lllllll}
\hline Pain in Abdomen & $\mathbf{0 ~ d}$ & $\mathbf{1 5}$ d & 30 d & 45 d & 60 d & \% difference \\
\hline 0 & $0(0 \%)$ & $1(2.5 \%)$ & $5(12.5 \%)$ & $10(25 \%)$ & $21(52.5 \%)$ & $52.5 \%$ \\
1 & $0(0 \%)$ & $12(30 \%)$ & $18(45 \%)$ & $26(65 \%)$ & $18(45 \%)$ & $45.0 \%$ \\
2 & $12(30 \%)$ & $18(45 \%)$ & $16(40 \%)$ & $4(10 \%)$ & $1(2.5 \%)$ & $-27.5 \%$ \\
3 & $28(70 \%)$ & $9(22.5 \%)$ & $1(2.5 \%)$ & $0(0 \%)$ & $0(0 \%)$ & $-70.0 \%$ \\
\hline
\end{tabular}




\begin{tabular}{lllllll}
\hline Total & $40(100 \%)$ & $40(100 \%)$ & $40(100 \%)$ & $40(100 \%)$ & $40(100 \%)$ & -
\end{tabular}

$\mathrm{P}<0.001 * *, 97.5 \%$ change, significant, paired proportion test

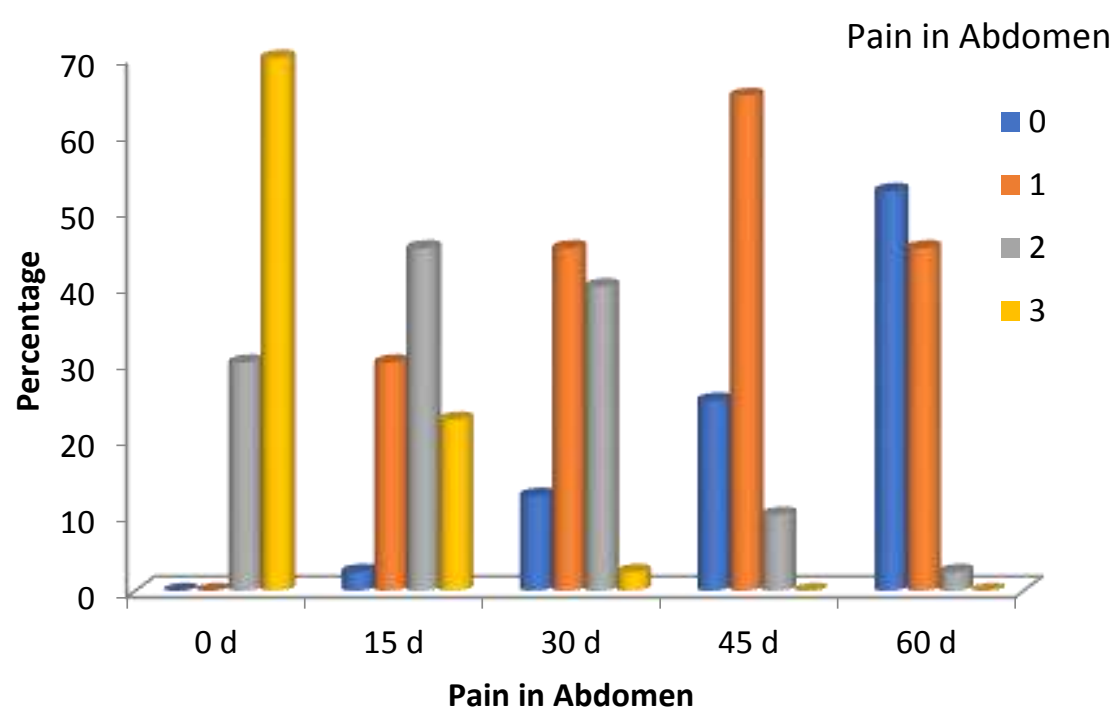

Table 3: Nausea \& Vomiting- An assessment at different time intervals of patients studied

\begin{tabular}{lllllll}
\hline $\begin{array}{l}\text { Nausea \& } \\
\text { Vomiting }\end{array}$ & $\mathbf{0 ~ d}$ & $\mathbf{1 5} \mathbf{d}$ & $\mathbf{3 0 ~ d}$ & $\mathbf{4 5} \mathbf{d}$ & $\mathbf{6 0 ~ d}$ & $\begin{array}{l}\text { \% } \\
\text { difference }\end{array}$ \\
\hline 0 & $1(2.5 \%)$ & $4(10 \%)$ & $12(30 \%)$ & $21(52.5 \%)$ & $32(80 \%)$ & $77.5 \%$ \\
1 & $3(7.5 \%)$ & $18(45 \%)$ & $23(57.5 \%)$ & $18(45 \%)$ & $8(20 \%)$ & $12.5 \%$ \\
2 & $16(40 \%)$ & $17(42.5 \%)$ & $4(10 \%)$ & $1(2.5 \%)$ & $0(0 \%)$ & $-40.0 \%$ \\
3 & $20(50 \%)$ & $1(2.5 \%)$ & $1(2.5 \%)$ & $0(0 \%)$ & $0(0 \%)$ & $-50.0 \%$ \\
Total & $40(100 \%)$ & $40(100 \%)$ & $40(100 \%)$ & $40(100 \%)$ & $40(100 \%)$ & - \\
\hline $0.001 * *, 90 \%$ change, significant, paired proportion test
\end{tabular}

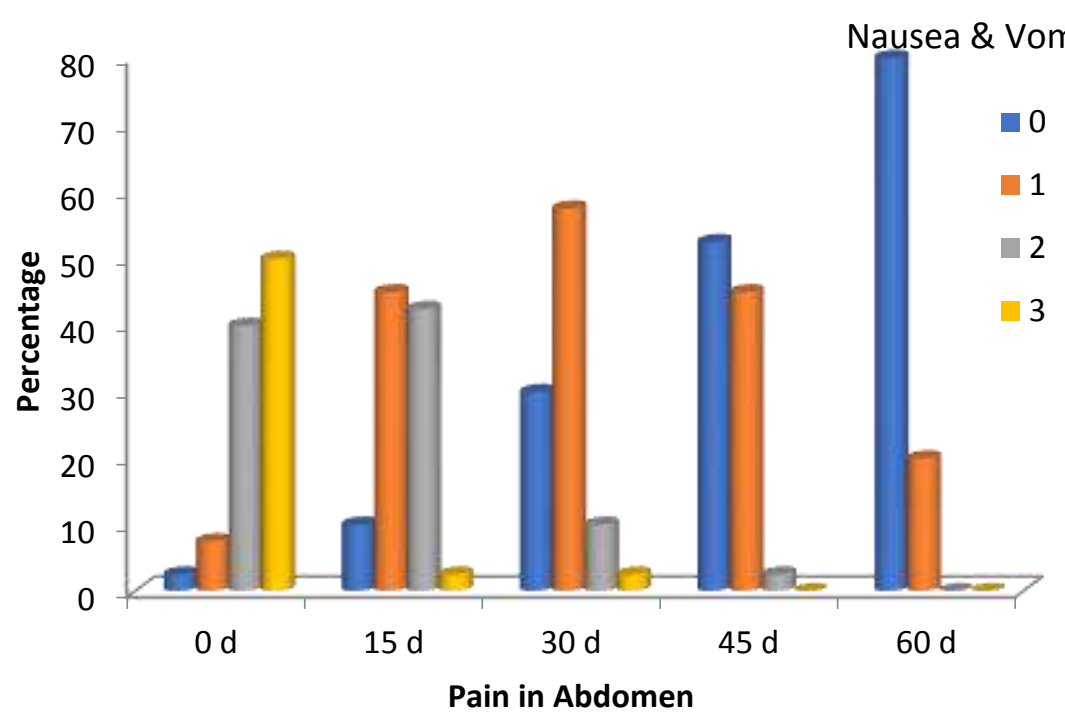


Table 4: Dyspepsia- An assessment at different time intervals of patients studied

\begin{tabular}{lllllll}
\hline Dyspepsia & 0 d & 15 d & 30 d & 45 d & 60 d & $\begin{array}{l}\text { \% } \\
\text { difference }\end{array}$ \\
\hline 0 & $0(0 \%)$ & $5(12.5 \%)$ & $14(35 \%)$ & $16(40 \%)$ & $40(100 \%)$ & $100.0 \%$ \\
1 & $3(7.5 \%)$ & $10(25 \%)$ & $16(40 \%)$ & $24(60 \%)$ & $0(0 \%)$ & $-7.5 \%$ \\
2 & $19(47.5 \%)$ & $21(52.5 \%)$ & $9(22.5 \%)$ & $0(0 \%)$ & $0(0 \%)$ & $-47.5 \%$ \\
3 & $18(45 \%)$ & $4(10 \%)$ & $1(2.5 \%)$ & $0(0 \%)$ & $0(0 \%)$ & $-45.0 \%$ \\
Total & $40(100 \%)$ & $40(100 \%)$ & $40(100 \%)$ & $40(100 \%)$ & $40(100 \%)$ & - \\
\hline \multicolumn{2}{l}{ P<0.001**, 100\% change, significant, paired proportion test } & &
\end{tabular}

Table 5: Loss of Appetite- An assessment at different time intervals of patients studied

\begin{tabular}{lllllll}
\hline $\begin{array}{l}\text { Loss of } \\
\text { Appetite }\end{array}$ & $\mathbf{0 ~ d}$ & $\mathbf{1 5} \mathbf{d}$ & $\mathbf{3 0 ~ d}$ & $\mathbf{4 5} \mathbf{d}$ & $\mathbf{6 0 ~ d}$ & $\begin{array}{l}\% \\
\text { difference }\end{array}$ \\
\hline 0 & $0(0 \%)$ & $2(5 \%)$ & $11(27.5 \%)$ & $23(57.5 \%)$ & $26(65 \%)$ & $65.0 \%$ \\
1 & $0(0 \%)$ & $15(37.5 \%)$ & $25(62.5 \%)$ & $15(37.5 \%)$ & $13(32.5 \%)$ & $32.5 \%$ \\
2 & $19(47.5 \%)$ & $20(50 \%)$ & $4(10 \%)$ & $2(5 \%)$ & $1(2.5 \%)$ & $-45.0 \%$ \\
3 & $21(52.5 \%)$ & $3(7.5 \%)$ & $0(0 \%)$ & $0(0 \%)$ & $0(0 \%)$ & $-52.5 \%$ \\
Total & $40(100 \%)$ & $40(100 \%)$ & $40(100 \%)$ & $40(100 \%)$ & $40(100 \%)$ & - \\
\hline
\end{tabular}

Table 6: USG Whole Abdomen- An assessment at different time intervals of patients studied

\begin{tabular}{llll}
\hline $\begin{array}{l}\text { USG Whole } \\
\text { Abdomen }\end{array}$ & $\begin{array}{l}\text { Before } \\
\text { Treatment }\end{array}$ & $\begin{array}{l}\text { After } \\
\text { Treatment }\end{array}$ & $\begin{array}{l}\% \\
\text { difference }\end{array}$ \\
\hline Absent & $0(0 \%)$ & $31(77.5 \%)$ & $77.5 \%$ \\
Present & $40(100 \%)$ & $9(22.5 \%)$ & $-77.5 \%$ \\
Total & $40(100 \%)$ & $40(100 \%)$ & - \\
\hline \multicolumn{2}{c}{$\mathrm{P}<0.001 * *$} & 77.5\% change, significant, paired proportion test
\end{tabular}

Table 7: CT-Scan- An assessment of Inflammation at different time intervals of patients studied

\begin{tabular}{llll}
\hline CT-Scan & Before Treatment & After Treatment & \% difference \\
\hline Absent & $0(0 \%)$ & $32(80 \%)$ & $80.0 \%$ \\
Present & $40(100 \%)$ & $8(20 \%)$ & $-80.0 \%$ \\
Total & $40(100 \%)$ & $40(100 \%)$ & - \\
\hline \multicolumn{2}{r}{$\mathrm{P}<0.001^{* *}, 80.0 \%$ change, significant, paired proportion test }
\end{tabular}

Table 8: Comparison of clinical variables before and after treatment of patients studied

\begin{tabular}{llllll}
\hline variables & $\begin{array}{l}\text { Before } \\
\text { Treatment }\end{array}$ & $\begin{array}{l}\text { After } \\
\text { Treatment }\end{array}$ & difference & $\begin{array}{l}\text { t } \\
\text { value }\end{array}$ & P value \\
\hline Hemoglobin \% & $13.02 \pm 1.50$ & $13.90 \pm 1.53$ & -0.880 & -4.468 & $<0.001^{* *}$ \\
TLC & $8232.50 \pm 1669$ & $7290.00 \pm 1619$ & 942.500 & 3.197 & $0.003^{* *}$ \\
Polymorphs & $57.13 \pm 6$ & $55.40 \pm 6.90$ & 1.725 & 1.705 & $0.096+$ \\
Lymphocyte & $35.45 \pm 6$ & $32.40 \pm 6.91$ & 3.050 & 3.416 & $0.001^{* *}$ \\
Eosinophil & $4.25 \pm 1.0$ & $4.15 \pm 0.89$ & 0.100 & 0.539 & 0.593 \\
Monocytes & $3.43 \pm 1.0$ & $3.98 \pm 0.97$ & -0.550 & -2.527 & $0.016^{*}$ \\
Serum Bilirubin & $1.13 \pm 0.13$ & $1.04 \pm 0.07$ & 0.090 & 3.636 & $0.001^{* *}$ \\
\hline \hline www.ajphr.com & & & & & \\
\hline
\end{tabular}




\begin{tabular}{llllll}
\hline Blood Urea $(\mathrm{mg} / \mathrm{dl})$ & $36.28 \pm 4.19$ & $33.05 \pm 4.03$ & 3.225 & 4.038 & $<0.001^{* *}$ \\
$\begin{array}{l}\text { Serum Creatinine } \\
(\mathrm{mg} / \mathrm{dl})\end{array}$ & $0.97 \pm 0.12$ & $0.96 \pm 0.12$ & 0.015 & 1.183 & 0.244 \\
SGOT & & & & & \\
SGPT & $28.25 \pm 7.75$ & $23.55 \pm 8.64$ & 4.700 & 4.603 & $<0.001^{* *}$ \\
\hline
\end{tabular}

Student t test (Two tailed, Dependent)

Table 9: UR-Comparison before and after treatment of patients studied

\begin{tabular}{llll}
\hline UR & $\begin{array}{l}\text { Before } \\
\text { Treatment }\end{array}$ & $\begin{array}{l}\text { After } \\
\text { Treatment }\end{array}$ & $\begin{array}{l}\text { \% } \\
\text { difference }\end{array}$ \\
\hline Nil & $37(92.5 \%)$ & $38(95 \%)$ & $2.5 \%$ \\
Yes & $3(7.5 \%)$ & $2(5 \%)$ & $-2.5 \%$ \\
Total & $40(100 \%)$ & $40(100 \%)$ & - \\
\hline 454, 2.5\% change, Not significant, paired proportion test
\end{tabular}

Table 10: UM- Comparison before and after treatment of patients studied

\begin{tabular}{llll}
\hline UM & Before Treatment & After Treatment & \% difference \\
\hline Nil & $40(100 \%)$ & $40(100 \%)$ & $0.0 \%$ \\
Yes & $0(0 \%)$ & $0(0 \%)$ & $0.0 \%$ \\
Total & $40(100 \%)$ & $40(100 \%)$ & - \\
\hline \multicolumn{2}{r}{$\mathrm{P}=1.000$, No Change, Not significant, paired proportion test }
\end{tabular}

\section{Statistical Methods:}

Descriptive and inferential statistical analysis has been carried out in the present study. Results on continuous measurements are presented on Mean \pm SD (Min-Max) and results on categorical measurements are presented in Number (\%). Significance is assessed at $5 \%$ level of significance. The following assumptions on data is made, Assumptions: 1. Dependent variables should be normally distributed, 2. Samples drawn from the population should be random, Cases of the samples should be independent

Student $\mathrm{t}$ test (two tailed, dependent) has been used to find the significance of study parameters on continuous scale with in each group.

Chi-square/ Fisher Exact test has been used to find the significance of study parameters on categorical scale between two or more groups, Non-parametric setting for Qualitative data analysis. Fisher exact test used when cell samples are very small.

Paired Proportion test has been used to find the significance of proportion in paired data. Smaller percentage of Improvement becomes significant at lower tail compared to higher tail. Eg. Improvement from $10 \%$ to $20 \%$ is difficult than the Improvement from $80 \%$ to $90 \%$ https://home.ubalt.edu/ntsbarsh/Business-stat/otherapplets/PairedProp.htm

\section{Significant figures}

+ Suggestive significance $(\mathrm{P}$ value: $0.05<\mathrm{P}<0.10)$ 
* Moderately significant ( $\mathrm{P}$ value:0.01<P $\leq 0.05$ )

** Strongly significant ( $\mathrm{P}$ value: $\mathrm{P} \leq 0.01)$

\section{Statistical software:}

The Statistical software namely SPSS 18.0, and R environment ver.3.2.2 were used for the analysis of the data and Microsoft word and Excel have been used to generate graphs, tables etc.

\section{DISCUSSION}

The present clinical study entitled "Clinical or Surgical Study of Warm-e- Marara (Cholecystitis)" was conducted at OPDs of DUMC Hospital \& Research Centre, Deoband (UP) from June 2017 to September 2018. The study was executed after obtaining approval of the study protocol from the Institutional Ethical Committee, Deoband Unani Medical College, Hospital \& Research Centre, Deoband. The study protocol comprises of following subheadings.

Mizaj distribution of patients studied:

28(70\%) patients of cholecystitis were Safravi Mizaj and 8(20\%) were Saudavi Mizaj and 3(7.5\%) in Damvi Mizaj (Table No. 1). This finding is coinciding with the observation made by Hakim Akbar Arzani, Hakim Azam Khan in their Classical text Iksire Azam and Tibbe Akbar. i..e. Warm-e-Marara is common among Safravi Mizaj. ${ }^{25,26}$

\section{Effect of Research Drug on Subjective parameters:}

\section{Pain in Abdomen:}

Pain associated with Warm-e-Marara was found in all the 40 patients when enrolled in the study, 12 patients had severe pain and 12 had mild pain. After the administration of the test drugs it was found that there was $70 \%$ reduction in severe pain and only 9 patients had severe pain whereas pain was reduced to moderate and mild in 9 and 18 patients and one patient had no pain. The pain subsided continuously till sixty day of treatment. On sixty day only one patient had severe pain and 21 patients had no pain, 18 patients had mild pain. When the pre and post treatment data was analyzed statistically using chi square test for proportions the pain reduction was significant $(\mathrm{p}<0.001)$ in post treated group. (Table No. 2). The effect was due to various drugs present in the Joshanda, Sharbat Bazoori Motadil and Majoon Dabeedulward. SBM is established diuretic and the ingredients have documented anti-inflammatory activity. ${ }^{25,26,27,28}$

\section{Nausea \& Vomiting:}

Nausea \& vomiting associated with Warm-e-Marara was found in all the 39 patients when enrolled in the study.20 patients had severe nausea \& vomiting and 16 had mild nausea \& vomiting. After the administration of the test drugs it was found that there was $50 \%$ reduction in 
severe nausea \& vomiting and only 1 patients had severe nausea $\&$ vomiting whereas nausea $\&$ vomiting was reduced to moderate and mild in 17 and 18 patients, respectively and one patient had no nausea \& vomiting. The nausea \& vomiting subsided continuously till sixty day of treatment. On sixty day only one patient had severe nausea \& vomiting and 32 patients had no nausea $\&$ vomiting, 8 patients had mild nausea \& vomiting. When the pre and post treatment data was analyzed statistically using chi square test for proportions the nausea \& vomiting reduction was significant $(\mathrm{p}<0.001)$ in post treated group. (Table No. 3). The effect was due to various drugs present in the Joshanda, Sharbat Bazoori Motadil and Majoon Dabeedulward. SBM is established diuretic and the ingredients have documented anti-inflammatory activity. $25,26,27,28$

\section{Dyspepsia:}

Dyspepsia associated with Warm-e-Mararah was found in all the 40 patients when enrolled in the study.18 patients had severe dyspepsia and 19 had moderate dyspepsia. 15 day after the administration of the test drugs it was found that there was $45 \%$ reduction in severe dyspepsia and only 4 patients had severe dyspepsia whereas dyspepsia was reduced to moderate and mild in 21 and 10 patients and five patient had no dyspepsia. The dyspepsia subsided continuously till sixty day of treatment. On sixty day no patient had dyspepsia. When the pre and post treatment data was analyzed statistically using chi square test for proportions the dyspepsia reduction was significant $(\mathrm{p}<0.001)$ in post treated group. (Table No. 4). The effect was due to various drugs present in the Joshanda, Sharbat Bazoori Motadil and Majoon Dabeedulward. SBM is established diuretic and the ingredients have documented anti-inflammatory activity. ${ }^{25,26,27,28}$

\section{Loss of Appetite:}

Loss of appetite associated with Warm-e-Mararah was found in all the 40 patients when enrolled in the study.21 patients had severe loss of appetite and 19 had mild severe loss of appetite. 15 day after the administration of the test drugs it was found that there was $32 \%$ reduction in loss of appetite and only 3 patients had severe loss of appetite whereas severe loss of appetite was reduced to moderate and mild in 20 and 15 patients and one patient had no severe loss of appetite. The severe loss of appetite subsided continuously till sixty day of treatment. On sixty day no patient had severe loss of appetite and 26 patients had no complaint of loss of appetite, 13 patients had mild and one had moderate loss of appetite. When the pre and post treatment data was analyzed statistically using chi square test for proportions the severe loss of appetite reduction was significant $(\mathrm{p}<0.001)$ in post treated group. (Table No. 5). The effect was due to various drugs present in the Joshanda, Sharbat Bazoori Motadil and Majoon Dabeedulward. 
SBM is established diuretic and the ingredients have documented anti-inflammatory activity. $25,26,27,28$

\section{Effect of Research Drug on Objective parameters:}

\section{USG Whole Abdomen:}

USG finding before treatment showed gall bladder enlargement in 40 patients and normal findings in none patient before administration of the test drugs. After the administration of the test drugs 31 patients had normal gall bladder whereas 9 patients had persisted with the enlargement of gall bladder. When the pre and post treatment patients USG findings was analyzed statistically using chi square test for proportions the inflammation reduction was significant $(\mathrm{p}<0.001)$ in post treated group. (Table No. 6). The effect was due to various drugs present in the Joshanda, Sharbat Bazoori Motadil and Majoon Dabeedulward. SBM is established diuretic and the ingredients have documented anti-inflammatory activity. ${ }^{25,26,27,28}$

\section{CT-Scan:}

CT scan finding before treatment showed gall bladder enlargement in 40 patients and normal findings in none patients before administration of the test drugs. After the administration of the test drugs 32 patients had normal gall bladder whereas 8 patient had persisted with the enlargement of gall bladder. When the pre and post treatment patients CT findings was analyzed statistically using chi square test for proportions the inflammation reduction was significant $(\mathrm{p}<0.001)$ in post treated group. (Table No. 7). The effect was due to various drugs present in the Joshanda, Sharbat Bazoori Motadil and Majoon Dabeedulward. SBM is established diuretic and the ingredients have documented anti-inflammatory activity. ${ }^{25,26,27,28}$

\section{Effect of Research Drug on Safety parameters}

All safety parameters as seen from the result data were found within normal range before and after the drug administration. (Table No. 8-10). The effect was due to various drugs present in the Joshanda, Sharbat Bazoori Motadil and Majoon Dabeedulward. SBM is established diuretic and the ingredients have documented anti-inflammatory activity. ${ }^{25,26,27,28}$ Moreover, MDW has been documented as liver tonic, anti-oxidant' and anti-cancer drug. ${ }^{25,26,27,28}$ Since Gall bladder is considered as part of liver in Unani and presently it has the function of concentrating bile salts, the above drugs may have acted upon the inflammation in the similar way as in Hepatitis. The study is observational one with 40 patients. It had inherent limitation of confounding. Further research is needed in large number of patients with suitable control group to fine tune the results obtained from present study. 


\section{CONCLUSION}

The findings about the parameters suggest that the test drug was effective in Warm-e-Mararah and the cure was substantial. The effect was due to various drugs present in the Joshanda, Sharbat Bazoori Motadil and Majoon Dabeedulward. SBM is established diuretic and the ingredients have documented anti-inflammatory activity. Moreover, MDW has been documented as liver tonic, anti-oxidant' and anti-cancer drug. Since Gall bladder is considered as part of liver in Unani and presently it has the function of concentrating bile salts, the above drugs may have acted upon the inflammation in the similar way as in Hepatitis.

The subjective parameters of pain in abdomen, nausea \& vomiting, dyspepsia and loss of appetite, were satisfactorily alleviated by the test drugs and all the findings found in USG and CT scan were also seen to subside with in the protocol duration.

The findings about the parameters suggest that the test drug was effective in Warm-e-Mararah and the cure was substantial. It reduced the subjective parameters as well as the findings in USG and CT scan of the Warm-e-Merarah patients.

The study is observational one with 40 patients. It had inherent limitation of confounding. Further research is needed in large number of patients with suitable control group to fine tune the results obtained from present study.

\section{SUMMARY}

The present clinical study entitled "Clinical or Surgical Study of Warm-e-Marara (Cholecystitis)" was conducted at OPDs of DUMC Hospital \& Research Centre, Deoband (UP) from June 2017 to September 2018. The study was executed after obtaining approval of the study protocol from the Institutional Ethical Committee, Deoband Unani Medical College, Hospital \& Research Centre, Deoband. The study protocol comprises of following subheadings.

Mizaj distribution of patients studied:

28(70\%) patients of cholecystitis were Safravi Mizaj and 8(20\%) were Saudavi Mizaj and $3(7.5 \%)$ in Damvi Mizaj.

Effect of Research Drug on Subjective parameters:

\section{Pain in Abdomen:}

Pain associated with Warm-e-Mararah was found in all the 40 patients when enrolled in the study, 12 patients had severe pain and 12 had mild pain. After the administration of the test drugs it was found that there was $70 \%$ reduction in severe pain.

Nausea \& Vomiting: 
Nausea \& vomiting associated with Warm-e-Mararah was found in all the 39 patients when enrolled in the study.20 patients had severe nausea \& vomiting and 16 had mild nausea \& vomiting. After the administration of the test drugs it was found that there was $50 \%$ reduction in severe nausea \& vomiting.

\section{Dyspepsia:}

Dyspepsia associated with Warm-e-Mararah was found in all the 40 patients when enrolled in the study.18 patients had severe dyspepsia and 19 had moderate dyspepsia. 15 day after the administration of the test drugs it was found that there was $45 \%$ reduction in severe dyspepsia.

\section{Loss of Appetite:}

Loss of appetite associated with Warm-e-Mararah was found in all the 40 patients when enrolled in the study. 21 patients had severe loss of appetite and 19 had mild severe loss of appetite. 15 day after the administration of the test drugs it was found that there was $32 \%$ reduction in loss of appetite.

\section{Effect of Research Drug on Objective parameters:}

\section{USG Whole Abdomen:}

USG finding before treatment showed gall bladder enlargement in - patients and normal findings in - patients before administration of the test drugs. After the administration of the test drugs 31 patients had normal gall bladder whereas 9 patient had persisted with the enlargement of gall bladder. When the pre and post treatment patients USG findings was analyzed statistically using chi square test for proportions the inflammation reduction was significant $(\mathrm{p}<0.001)$ in post treated group.

\section{CT-Scan:}

CT scan finding before treatment showed gall bladder enlargement in 40 patients and normal findings in none patients before administration of the test drugs. After the administration of the test drugs 32 patients had normal gall bladder whereas 8 patient had persisted with the enlargement of gall bladder. When the pre and post treatment patients CT findings was analyzed statistically using chi square test for proportions the inflammation reduction was significant $(\mathrm{p}<0.001)$ in post treated group.

\section{Effect of Research Drug on Safety parameters}

All the hematological parameters of $\mathrm{Hb} \%$, TLC and DLC, Liver function parameters of SGOT and SGPT, and kidney function parameters of blood Urea and serum creatinine as seen from the result data were found within normal range before and after the drug administration. 


\section{REFERENCE}

1. Williams NS, Bulstrode CJK et al. Bailey \& Loves Short practice of surgery, $25^{\text {th }}$ Edition, UK, Edward Arnold Publisher Ltd. 2008:1299.

2. Jones MW, Bhimji SS. Gallbladder, Cholecystitis, Acute. Stat Pearls Publishing; 2018.

3. Jones MW, Ferguson T. Gallbladder, Cholecystitis, Chronic. Stat Pearls Publishing; 2018.

4. Knab LM, Boller AM et al. Cholecystitis. Surg Clin North Am. 2014; 94(2):455-70.

5. Liu $\mathbf{J}$ et al. Acute cholecystitis associated with infection of Enterobacteriaceae from gut microbiota. Clin Microbiol Infect. 2015;21(9):851.e1-9.

6. Indar AA, Beckingham IJ. Acute cholecystitis. BMJ. 2002; 325(7365): 639-643.

7. Gomes CA et al. Acute calculous cholecystitis: Review of current best practices. World J Gastrointest Surg. 2017; 9(5): 118-126.

8. Henao-Morán S, Denova-Gutiérrez E et al. Recreational physical activity is inversely associated with asymptomatic gallstones in adult Mexican women. Ann Hepatol. 2014; 13(6):810-8.

9. Khuroo MS. Ascariasis.Gastroenterol Clin North Am. 1996; 25(3):553-77.

10. Stinton LM, Shaffer EA. Epidemiology of Gallbladder Disease: Cholelithiasis and Cancer. Gut Liver. 2012; 6(2): 172-187.

11. Kaminski DL, Deshpande Y et al. Effect of oral ibuprofen on formation of prostaglandins E and F by human gallbladder muscle and mucosa. Dig Dis Sci. 1985; 30(10):933-40.

12. Masahiro Yoshida et al. Antimicrobial therapy for acute cholecystitis: Tokyo Guidelines. J Hepatobiliary Pancreat Surg. 2007; 14(1): 83-90.

13. Janowitz P, Kratzer $W$ et al. Gallbladder sludge: spontaneous course and incidence of complications in patients without stones. Hepatology. 1994; 20:291-294.

14. Cheruvu CV, Eyre-Brook IA. Consequences of prolonged wait before gallbladder surgery. Ann R Coll Surg Engl. 2002; 84:20-22.

15. Katabathina VS, Zafar AM et al. linical Presentation, Imaging, and Management of Acute Cholecystitis. Tech Vasc Interv Radiol. 2015; 18(4):256-65.

16. Draghi F, Ferrozzi G et al. Power Doppler ultrasound of gallbladder wall vascularization in inflammation: clinical implications. Eur Radiol. 2000; 10:1587-90.

17. Halldestam I, Kullman E et al. Defined indications for elective cholecystectomy for gallstone disease. Br J Surg. 2008; 95(5):620-6. 
18. Acar $\mathrm{T}$ et al. Laparoscopic cholecystectomy in the treatment of acute cholecystitis: comparison of results between early and late cholecystectomy. Pan Afr Med J. 2017; 26: 49.

19. To KB, Cherry-Bukowiec JR et al. Emergent versus elective cholecystectomy: conversion rates and outcomes. Surg Infect (Larchmt). 2013;14(6):512-9.

20. Berger H, Pratschke E et al. Percutaneous cholecystectomy in acute a calculous cholecystitis. Hepatogastroenterology. 1989; 36:346-348.

21. Pinto A et al. Accuracy of ultrasonography in the diagnosis of acute calculous cholecystitis: review of the literature. Crit Ultrasound J. 2013; 5(Suppl 1): S11.

22. Shakespear JS, Shaaban AM et al. CT findings of acute cholecystitis and its complications. AJR Am J Roentgenol. 2010; 194(6):1523-9.

23. Tripathi KD. Essentials of medical pharmacology. $7^{\text {th }}$ ed. Jaypee Brother Medical Publication; 2013:634-644.

24. Sina I. Al Qanoon fit Tib (Urdu translation by Kantoori GH). Vol. 4. New Delhi: Azaj Publishing house. YNM. 1444-1447.

25. Khan A. Iksir-e-Azam. Idarah Kitab Us Shifa New Delhi. 2011.

26. AlamA, Ahmed Z et al. Time Tested Safe and Effect Oriented Drugs in Unani Medicine for Dyslipidemia-A Review. J Homeop Ayurv Med. 2015; 4:176.

27. Kabeeruddin HM. BiyazKabir. Vol-2, Hikmat Book Depo, Hyderabad. YNM:5

28. Anonymous. The Unani Pharmacopoeia of India. Part-II, Volume-I. Published by Govt. Of India Ministry of Health and Family Welfare, Dept. Of AYUSH New Delhi.2009:7173. 